\title{
Effect of 2-Mercapto-5-benzimidazolesulfonic Acid in Superconformal Cu Electroless Deposition
}

\author{
Chang Hwa Lee, ${ }^{\text {a,* }}$ Ae Rim Kim, Hyo-Chol Koo, ${ }^{*}$ and Jae Jeong Kim**,z \\ Research Center for Energy Conversion and Storage, School of Chemical Engineering, \\ College of Engineering, Seoul National University, Seoul 151-742, Korea
}

\begin{abstract}
Superconformal $\mathrm{Cu}$ electroless deposition is demonstrated in a $\mathrm{CuSO}_{4}-\mathrm{EDTA}-\mathrm{HCHO}$ (where EDTA is ethylenediaminetetraacetic acid) electrolyte containing 2-mercapto-5-benzimidazolesulfonic acid (MBIS). MBIS reveals a concentration-dependent effect in the deposition rate on planar substrates, whereby acceleration at low concentration and suppression at high concentration are evident. The half-cell reaction experiments show that the acceleration effect of MBIS is mainly associated with the cathodic reaction, while MBIS inhibits the oxidation of $\mathrm{HCHO}$ in the anodic reaction. The addition of $\mathrm{MBIS}$ offers preferential $\mathrm{Cu}$ electroless deposition at the bottom of $500 \mathrm{~nm}$ wide trenches. Poly(ethylene glycol) improved the surface roughness, maintaining the shape evolution of superconformal feature filling.

(C) 2009 The Electrochemical Society. [DOI: 10.1149/1.3117343] All rights reserved.
\end{abstract}

Manuscript submitted December 9, 2008; revised manuscript received February 3, 2009. Published April 21, 2009.

Superconformal $\mathrm{Cu}$ electrodeposition has been successfully implemented in the metallization of electronic devices, thereby enabling the buildup of multilevel interconnects for ultralarge-scale integration (ULSI). ${ }^{1}$

Electroless $\mathrm{Cu}$ deposition has been mainly used in an area of printed circuit boards to form seed layers (conductive path) for $\mathrm{Cu}$ electrodeposition in high aspect ratio through-holes, taking advantage of its ability to metallize nonconductive epoxy glasses, polyimides, etc. ${ }^{2,3}$ Recent research on $\mathrm{Cu}$ electroless deposition has extended its application to seed layer deposition for $\mathrm{Cu}$ electrodeposition in ULSI interconnect fabrication, with increasing advantages over alternative methods as the feature size decreases to a submicrometer scale. ${ }^{4,5}$ Electroless deposition is a surface limited reaction that enables the deposition of considerably thin and uniform $\mathrm{Cu}$ seed layers with a superior step coverage compared to physical vapor deposition (PVD) or chemical vapor deposition seed layers. ${ }^{6,7}$ Contrary to the conventional method that utilizes a conformal deposition property of electroless $\mathrm{Cu}$, a superfilling of submicrometer features such as trenches or vias using only electroless deposition has also been attempted in several publications. ${ }^{8-12}$ The most important factor that determines the feature-filling profiles is the effect of additives. In electrodeposition, a quantitative understanding of superconformal electrodeposition can be described by the curvature enhanced accelerator coverage (CEAC) mechanism that is derived from the competitive adsorption between additive species that accelerate and inhibit the deposition rate coupled with electrode area change. ${ }^{13,14}$ The use of additives in $\mathrm{Cu}$ electroless deposition has been largely concerned with stabilizing the electrolyte or enhancing the physical properties of films, while the effect on feature filling has received less attention.

In previous work, we have achieved superconformal $\mathrm{Cu}$ electroless deposition in the presence of bis-(3-sulfopropyl)-disulfide $(\mathrm{SPS})^{9,10}$ and $3-N, N$-dimethylamino-dithiocarbamoyl-1-propanesulfonic acid (DPS) ${ }^{8,15}$ that showed concentration-dependent effects in terms of the deposition rate (i.e., acceleration at low concentration and suppression at high concentration). The additive concentration difference between the bottom and the free surface of trenches under the diffusion limited condition is believed to give rise to superconformal feature filling. Although bumps, evidence of bottom-up fill, have been experimentally observed for both SPS and DPS cases, ${ }^{8,9}$ the reaction mechanism is definitely different from that in $\mathrm{Cu}$ electrodeposition because the reducing agent such as $\mathrm{HCHO}$ is used to

\footnotetext{
* Electrochemical Society Student Member.

** Electrochemical Society Active Member.

${ }^{a}$ Present address: Metallurgy Division in Materials Science and Engineering Laboratory, National Institute of Standards and Technology, Gaithersburg, MD 20899, USA.

z E-mail: jjkimm@snu.ac.kr
}

supply electrons for the reduction of $\mathrm{Cu}$ complex ions, and the additives can affect the activity of the HCHO oxidation process.

In this paper, we employ an additive, 2-mercapto-5benzimidazolesulfonic acid (MBIS) in $\mathrm{Cu}$ electroless deposition. The concentration effect of MBIS is investigated though half-cell experiments. Superconformal feature filling is demonstrated using MBIS in $\mathrm{Cu}$ electroless deposition.

\section{Experimental}

To examine the concentration effect of MBIS in $\mathrm{Cu}$ electroless deposition, both planar and trench-patterned p-type Si substrates were used. The planar substrates were prepared by PVD of TiN (10 $\mathrm{nm}) / \mathrm{Ti}(15 \mathrm{~nm})$ layers followed by PVD of $\mathrm{Cu}(60 \mathrm{~nm})$ for electrochemical analyses and film growth experiments. Before the deposition, the native $\mathrm{Cu}$ oxide was removed with a solution consisting of $3.8 \mathrm{~g} / \mathrm{L}$ citric acid and $10 \mathrm{~mL} / \mathrm{L} \mathrm{H}_{2} \mathrm{O}_{2}$ for $15 \mathrm{~s}$. For the feature-filling experiments, we used $500 \mathrm{~nm}$ midheight wide trench-patterned substrates with an aspect ratio of 2.5 , which were covered with TiN (10 $\mathrm{nm}) / \mathrm{Ti}(15 \mathrm{~nm})$ without $\mathrm{Cu}$ seed layers. The surface of the patterned substrate was pretreated by a 1:100 diluted HF solution to remove the native oxide, followed by the Pd activation process in a solution containing $0.1 \mathrm{~g} / \mathrm{L}$ palladium dichloride $\left(\mathrm{PdCl}_{2}\right), 5 \mathrm{~mL} / \mathrm{L} \mathrm{HF}(50 \%)$, and $3 \mathrm{~mL} / \mathrm{L}$ hydrochloric acid $(\mathrm{HCl}, 35 \%)$ for $20 \mathrm{~s}$ at room temperature.

$\mathrm{Cu}$ electroless deposition was carried out on both $\mathrm{Cu}$ seeded planar and Pd-activated TiN-patterned substrates in the electrolyte composed of $0.025 \mathrm{M}$ copper sulfate $\left(\mathrm{CuSO}_{4} \cdot 5 \mathrm{H}_{2} \mathrm{O}\right), 0.054 \mathrm{M}$ ethylenediaminetetraacetic acid (EDTA), and $0.078 \mathrm{M}$ paraformaldehyde $(\mathrm{HCHO})_{\mathrm{n}}$, adjusting the $\mathrm{pH}$ to 12.6 with $\mathrm{KOH}$ at $70^{\circ} \mathrm{C}$. The concentration of MBIS was varied from 0 to $3.0 \mathrm{mg} / \mathrm{L}$, and $2,2^{\prime}$-dipyridyl was fixed at $0.1 \mathrm{~g} / \mathrm{L}$ as a stabilizer. Poly(ethylene glycol) (PEG, Mw = 8000) was included in the experiment for the time evolution of feature filling to improve the surface roughness.

For the half-cell reaction experiments, linear sweep voltammetry was performed using Versastat II (EG\&G) with a saturated calomel electrode as a reference electrode and a $\mathrm{Pt}$ wire as an anode. Voltammetric curves were obtained in the $\mathrm{CuSO}_{4}$, EDTA, and $\mathrm{KOH}$ solution for a cathodic reaction and in the $\mathrm{HCHO}$, EDTA, and $\mathrm{KOH}$ solution for an anodic reaction in the presence of various MBIS concentrations. The electrochemical measurement was performed at a temperature of $25^{\circ} \mathrm{C}$. Field-emission-scanning electron microscopy (FESEM, JEOL 6330F) was utilized to measure the film thickness and to observe the cross section of trenches. The resistivities were calculated from sheet resistances measured by a four-point probe (Chang Min CMT-SR 1000N) and the film thickness.

\section{Results and Discussion}

$\mathrm{Cu}$ electroless deposition was performed on planar substrates with various concentrations of MBIS. The deposition time was fixed 
(a)

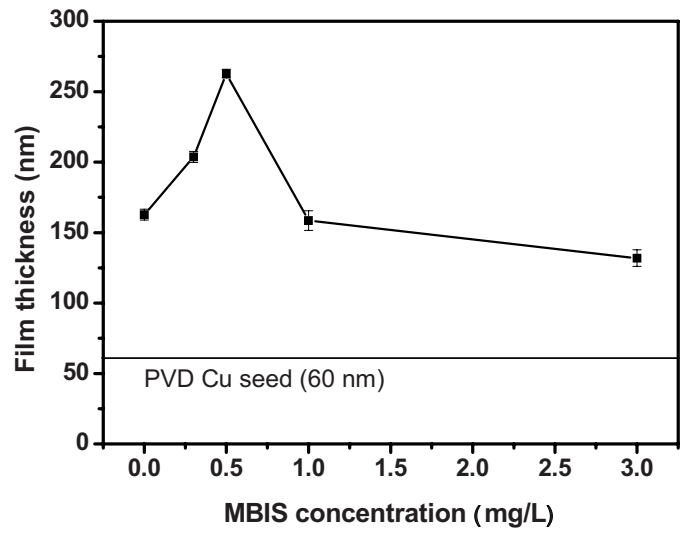

(b)

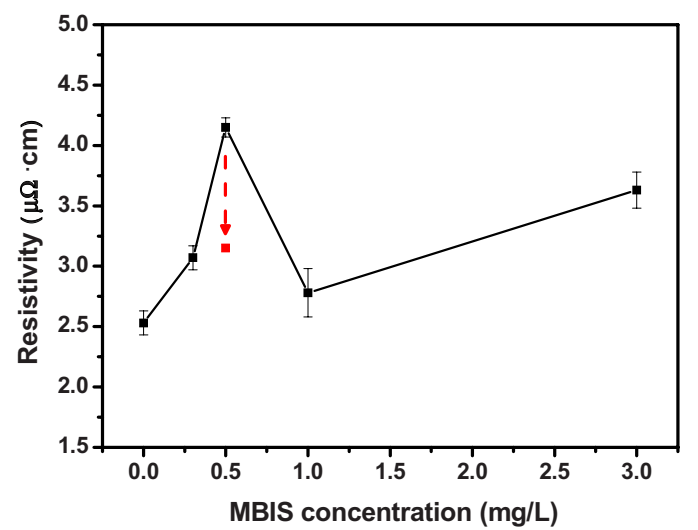

Figure 1. (Color online) Concentration-dependent effect of MBIS in $\mathrm{Cu}$ electroless deposition; (a) film thickness and (b) film resistivity. Deposition was performed for $5 \mathrm{~min}$ at $70^{\circ} \mathrm{C}$. The resistivity of the film deposited at 0.5 $\mathrm{mg} / \mathrm{L}$ MBIS was decreased down to $3.15 \mu \Omega \mathrm{cm}$ through the heat-treatment at $400^{\circ} \mathrm{C}$ for 30 min under $\mathrm{N}_{2}$ atmosphere [single dot below the arrow in (b)].

at 2.5 min for each concentration, and the film thickness was measured by FESEM, as shown in Fig. 1a. The deposition rate is accelerated with an initial increase in MBIS concentration, showing a maximum thickness value at $0.5 \mathrm{mg} / \mathrm{L}$. However it decreases at 1.0 $\mathrm{mg} / \mathrm{L}$, and the film growth is inhibited at a higher concentration (i.e., $3.0 \mathrm{mg} / \mathrm{L}$ ) with increased standard deviations in the film thickness. Although the deposition rate can be affected by the operating temperature, $\mathrm{pH}$, agitation, and type of reducing agent, the effects of additive concentration have also received attention in the electroless deposition process, as referred to in Ref. 16-20. The accelerating effect at low additive concentrations is derived from the rearrangement of $\mathrm{Cu}-$ EDTA complex ions. The delocalized electron of a strongly adsorbed additive facilitates $\mathrm{Cu}$ reduction by breaking the $\mathrm{Cu}$-ion-ligand bond. ${ }^{17,20}$ An excessively adsorbed additive through a specific functional group (i.e., thiols) hinders the catalytic site where the oxidation of $\mathrm{HCHO}$ occurs and inhibits the reduction of $\mathrm{Cu}$ ions. ${ }^{18,21}$

The resistivity of the films deposited on the $\mathrm{Cu}$ seed layer was calculated from the sheet resistance and the measured film thickness, as shown in Fig. 1b. The rough surface associated with the accelerated growth rate causes an increase in the resistivity even at low MBIS concentrations such as 0.3 and $0.5 \mathrm{mg} / \mathrm{L}$. As the MBIS concentration increases to $1.0 \mathrm{~g} / \mathrm{L}$, the resistivity is decreased due to the reduction in surface roughness. However it increases again at higher concentrations by substantial incorporation of MBIS into the deposit as well as thiolate compounds strongly adsorbed on the surface. In preliminary experiments, X-ray diffraction patterns confirmed the existence of $\mathrm{Cu}$ sulfides $\left[\mathrm{CuS}(103)\right.$ and/or $\left.\mathrm{Cu}_{2} \mathrm{~S}(200)\right]$ in the $\mathrm{Cu}$ film. The conductivity of the deposit can be improved by thermal annealing. For instance, in the case of the film deposited in the (a)

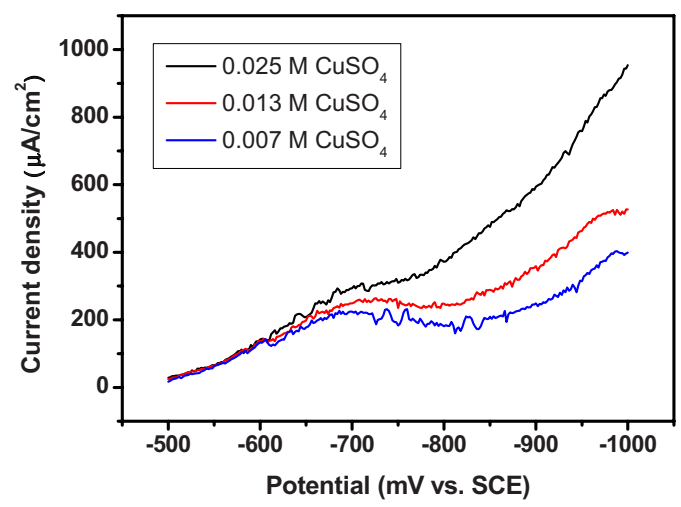

(b)

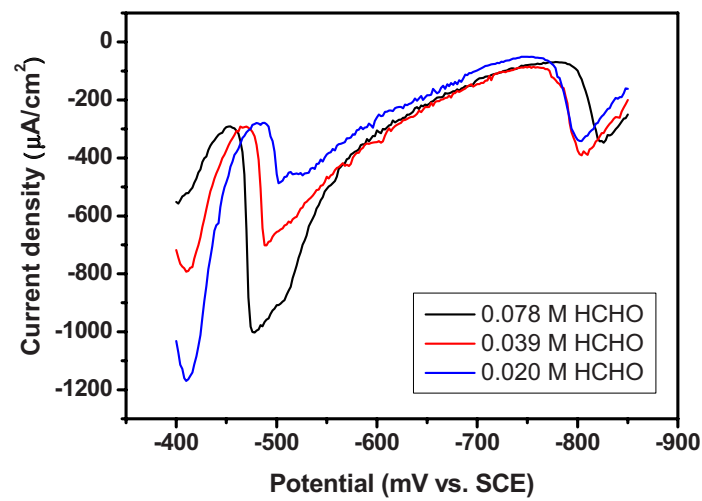

Figure 2. (Color online) Voltammetric curves for half-cell reactions in additive-free electrolytes; (a) negative potential sweep in the electrolyte containing various concentrations of $\mathrm{CuSO}_{4}$ and $0.054 \mathrm{M}$ EDTA and (b) positive potential sweep in the electrolyte containing various concentrations of $\mathrm{HCHO}$ and $0.054 \mathrm{M}$ EDTA. The $\mathrm{pH}$ of the solution was fixed at 12.6, and the temperature was maintained at $25^{\circ} \mathrm{C}$.

presence of $0.5 \mathrm{mg} / \mathrm{L}$ MBIS, the resistivity is decreased down to $3.15 \mu \Omega \mathrm{cm}$ through the heat-treatment at $400^{\circ} \mathrm{C}$ for $30 \mathrm{~min}$.

According to the mixed potential theory, the overall $\mathrm{Cu}$ electroless deposition reaction can be separated into two partial reactions consisting of cathodic and anodic reactions that occur simultaneously on the same substrate. ${ }^{2,3}$ The mechanism of electroless deposition can be simply understood by the mixed potential theory, although both reactions are known to be interdependent, showing an accelerating effect of $\mathrm{HCHO}$ intermediates such as methylene glycol for $\mathrm{Cu}$ reduction. 22,23

To examine the effect of MBIS on the respective partial reaction kinetics, linear sweep voltammetry was carried out. Figure 2 shows the voltammetric curves observed from an additive-free bath with varying concentration of $\mathrm{CuSO}_{4}$ and $\mathrm{HCHO}$. In the cathodic reaction, the positive current density is gradually increased (deposition) with a negatively increased potential. The peak position at $-0.7 \mathrm{~V}$, resulting from the reduction of cupric ions complexed with EDTA ${ }^{4-}$, decreases with decreasing $\mathrm{CuSO}_{4}$ concentration. The other major peaks around $-1.0 \mathrm{~V}$ reflect the cathodic hydrogen ion discharge from water. ${ }^{24}$ In the anodic reaction, the oxidation current of $\mathrm{HCHO}$ corresponding to around $-0.5 \mathrm{~V}$ is gradually decreased with decreasing $\mathrm{HCHO}$ concentration. At fixed $\mathrm{CuSO}_{4}$ and $\mathrm{HCHO}$ concentrations, the concentration of MBIS was varied from 0 to 3.0 $\mathrm{mg} / \mathrm{L}$ for each half-cell reaction, as presented in Fig. 3.

For the cathodic reaction, an increment of deposition rate is evident at 0.3 and $0.5 \mathrm{mg} / \mathrm{L}$ MBIS with a slight shift of peak potential toward positive values, whereas the growth velocity is decreased at high MBIS concentrations beyond $1.0 \mathrm{mg} / \mathrm{L}$. This shows a trend similar to the results observed in the film growth experiments. However the addition of MBIS leads only to a decrease in the kinetics for $\mathrm{HCHO}$ oxidation at the anode, which is most evident at high MBIS 
(a)

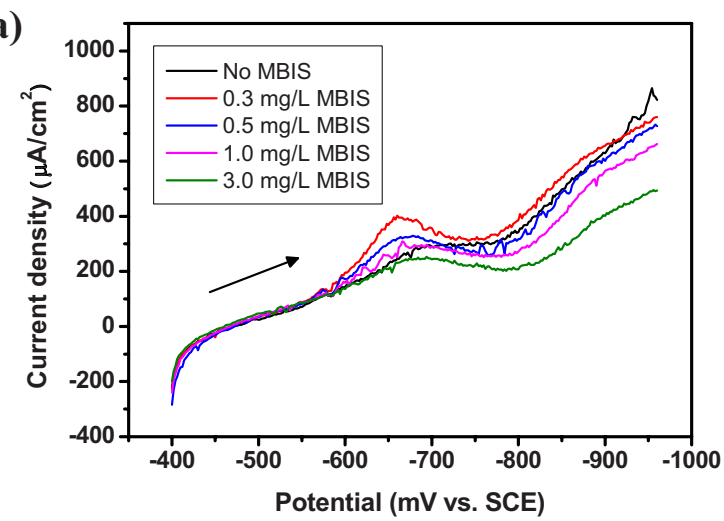

(b)

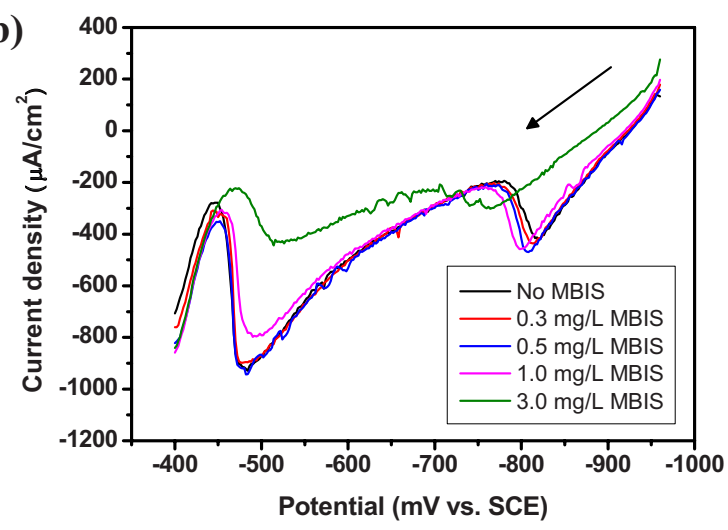

Figure 3. (Color online) Voltammetric curves for half-cell reactions in the presence of various MBIS concentrations ranging from 0 to $3.0 \mathrm{mg} / \mathrm{L}$. (a) Negative potential sweep in the electrolyte containing $0.025 \mathrm{M} \mathrm{CuSO}_{4}$ and $0.054 \mathrm{M}$ EDTA and (b) positive potential sweep in the electrolyte containing $0.078 \mathrm{M} \mathrm{HCHO}$ and $0.054 \mathrm{M}$ EDTA. The $\mathrm{pH}$ of the solution was fixed at 12.6 , and the temperature was maintained at $25^{\circ} \mathrm{C}$.

concentrations. This supports the assertion that the acceleration effect at low concentration is mainly associated with the cathodic reaction rather than the anodic reaction.

The attenuation of the anodic current can be explained by a strong adsorption of MBIS on the catalytic sites where the adsorption of methylene glycol anion occurs, simply blocking and/or deactivating the catalytic intermediates such as Reactions 4-6 in the following steps of the anodic reaction. ${ }^{6}$

Overall reaction: $2 \mathrm{HCHO}+4 \mathrm{OH}^{-} \rightarrow 2 \mathrm{HCOO}^{-}+2 \mathrm{H}_{2} \mathrm{O}+\mathrm{H}_{2}$ $+2 e^{-}($on $\mathrm{Cu}$ surface $)$

$$
\begin{gathered}
\mathrm{HCHO}+\mathrm{H}_{2} \mathrm{O} \rightarrow \mathrm{CH}_{2}(\mathrm{OH})_{2} \\
\mathrm{CH}_{2}(\mathrm{OH})_{2} \rightarrow \mathrm{CH}_{2}(\mathrm{OH}) \mathrm{O}^{-}+\mathrm{H}^{+} \\
\mathrm{CH}_{2}(\mathrm{OH})_{2}+\mathrm{OH}^{-} \rightarrow \mathrm{CH}_{2}(\mathrm{OH}) \mathrm{O}^{-}+\mathrm{H}_{2} \mathrm{O} \\
\mathrm{CH}_{2}(\mathrm{OH}) \mathrm{O}^{-} \rightarrow \mathrm{CH}_{2}(\mathrm{OH}) \mathrm{O}_{\mathrm{ads}}^{-}
\end{gathered}
$$

$$
\begin{gathered}
\mathrm{CH}_{2}(\mathrm{OH}) \mathrm{O}_{\mathrm{ads}}^{-} \rightarrow \mathrm{CH}(\mathrm{OH}) \mathrm{O}_{\mathrm{ads}}^{-}+\mathrm{H}_{\mathrm{ads}} \\
\mathrm{CH}_{2}(\mathrm{OH}) \mathrm{O}_{\mathrm{ads}}^{-}+\mathrm{OH}^{-} \rightarrow \mathrm{HCOO}^{-}+\mathrm{H}_{2} \mathrm{O}+e^{-} \\
2 \mathrm{H}_{\mathrm{ads}} \rightarrow \mathrm{H}_{2} \quad \text { (on } \mathrm{Cu} \text { surface) }
\end{gathered}
$$

Table I summarizes the mixed potential and the deposition current density measured by superimposing the voltammetric curves for cathodic and anodic reactions as a function of MBIS concentration. The deposition rate calculated from the reduction current $\left(i_{\text {dep }}\right.$ $=i_{\mathrm{c}}=-i_{\mathrm{a}}$ ) was compared with the average deposition rate directly measured from the film growth experiments shown in Fig. 1. The growth rate calculated from the partial reaction reveals a tendency similar to that of the average deposition rate with regard to the concentration effect of MBIS: acceleration at low concentration and suppression at high concentration. However the theoretical rates estimated from the half-cell reactions exhibit substantially reduced values compared to the deposition rate directly measured from the deposited film in a complete solution. The disparity of the deposition rate between the half-cell and film growth experiments can be ascribed to the catalytic effect of HCHO that greatly accelerates the reduction of $\mathrm{Cu}-\mathrm{EDTA}$ complex ions in the complete solution, ${ }^{22,23}$ which is excluded in the half-cell experiments, as well as to the different operating temperatures. Other variations associated with the interaction between anodic and cathodic partial reactions should also be considered.

In $\mathrm{Cu}$ electroless deposition, superconformal deposition has been investigated in the presence of various additives such as SPS and DPS that showed concentration-dependent acceleration and suppression effects on the planar substrate, as demonstrated in previous works. ${ }^{8,9}$ The formation of bumps on the center of trenches provides evidence that the additives play the role not only of a suppressor at the free surface but also of an accelerator at the bottom of trenches. Considering the concentration effect of the additives, the concentration difference between the bottom surface and the free surface by a local depletion of substantially diluted additives inside the trench may result in the superconformal feature filling in $\mathrm{Cu}$ electroless deposition.

Likewise, trench filling experiments were performed in $\mathrm{Cu}$ electroless deposition using MBIS. In the absence of MBIS, conformal film growth is evident along the entire surface profile, where the thicknesses on the sidewalls and the bottom surface are almost the same, as shown in Fig. 4a. However the addition of $1.0 \mathrm{mg} / \mathrm{L}$ MBIS reveals superconformal deposition. It is evident that the deposition on the free surface is greatly suppressed, while the trenches are completely filled with $\mathrm{Cu}$. (Fig. 4b) Although the acceleration at the bottom is not obvious at the MBIS concentration used in the experiment, Fig. $4 \mathrm{c}$ and d clearly show the preferential deposition of $\mathrm{Cu}$ at the bottom corners of trenches. The suppression effect at the protrusion of wide features is apparently similar to the conventional lev-

\begin{tabular}{|c|c|c|c|c|}
\hline $\begin{array}{l}\text { MBIS concentration } \\
(\mathrm{mg} / \mathrm{L})\end{array}$ & $\begin{array}{l}E_{\mathrm{mp}} \\
(\mathrm{mV})\end{array}$ & $\begin{array}{c}I_{\mathrm{dep}} \\
\left(\mathrm{mA} / \mathrm{cm}^{2}\right)\end{array}$ & $\begin{array}{l}\text { Calculated deposition rate } \\
(\mathrm{nm} / \mathrm{min})\end{array}$ & $\begin{array}{l}\text { Average deposition rate } \\
(\mathrm{nm} / \mathrm{min})\end{array}$ \\
\hline 0 & -696 & 0.296 & 6.57 & 41.1 \\
\hline 0.3 & -654 & 0.380 & 8.44 & 57.5 \\
\hline 0.5 & -680 & 0.328 & 7.28 & 81.1 \\
\hline 1.0 & -694 & 0.297 & 6.59 & 39.4 \\
\hline 3.0 & -712 & 0.244 & 5.42 & 28.7 \\
\hline
\end{tabular}
eling process that generally proceeds in larger dimensions. However the mechanism of superconformal filling in electroless deposition is expected to be more complex than leveling or CEAC models because it accompanies various reactions, including the reduction of $\mathrm{Cu}$ ions complexed with strong ligands and the oxidation reaction of $\mathrm{HCHO}$ that can be coupled with each other. 

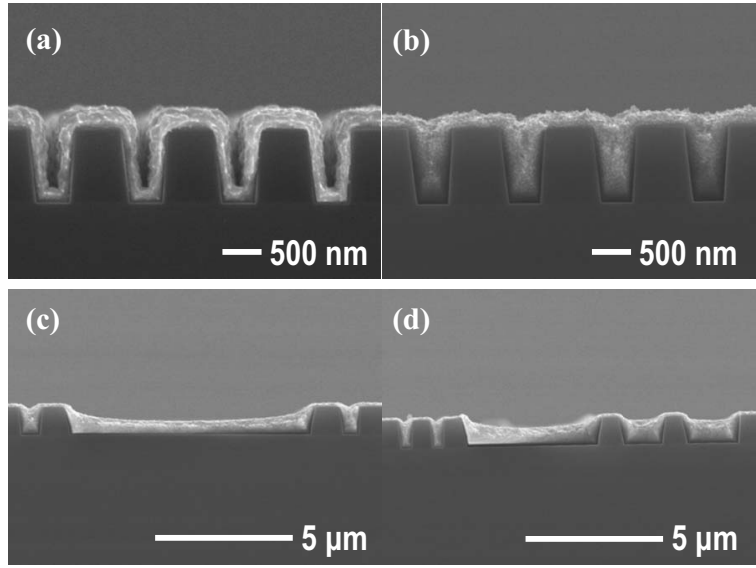

Figure 4. Cross section of trenches filled by electroless $\mathrm{Cu}$ deposition in the presence of (a) $0.1 \mathrm{~g} / \mathrm{L} 2,2^{\prime}$-dipyridyl and (b) $1.0 \mathrm{mg} / \mathrm{L}$ MBIS and $0.1 \mathrm{~g} / \mathrm{L}$ 2,2-dipyridyl. The deposition was performed at $70^{\circ} \mathrm{C}$ for (a) 5 and [(b)-(d)] $7 \mathrm{~min}$.

To obtain the shape evolution with the time of feature filling, cross sections of trenches were examined by FESEM in the presence of $1.0 \mathrm{mg} / \mathrm{L}$ MBIS, as shown in Fig. 5. To improve the surface roughness that may cause small voids inside narrower or higher aspect ratio trenches, PEG $(\mathrm{Mw}=8000)$ was included. Even though the deposition rate is decreased by the addition of PEG, the surface roughness exhibits a substantial improvement. The deposition profile presents conformal film growth at the initial filling for $5 \mathrm{~min}$; however the deposition rate begins to increase at the bottom corners after $8 \mathrm{~min}$, followed by continuous filling inside the trenches. The inhibition on the free surface is noticeable with a negligible increase in the thickness during a period of time (8-25 min), while the trench is filled from the bottom. Although the degradation of film conductivity associated with the incorporation of additional PEG is expected, it is considered to be effective in controlling the surface
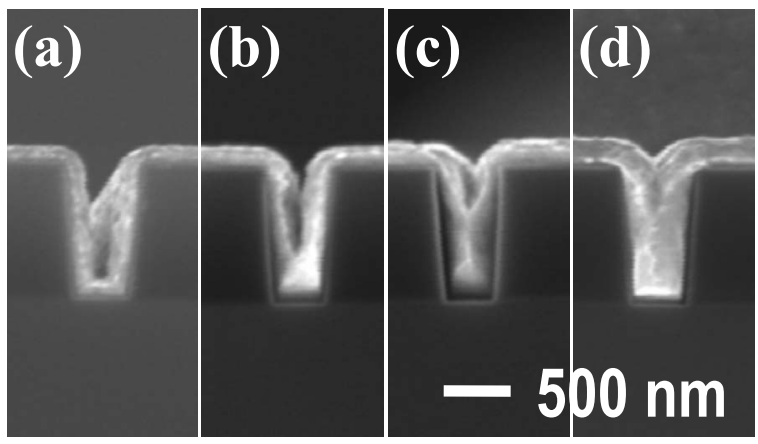

Figure 5. Time evolution of electroless $\mathrm{Cu}$ filling of trenches in the presence

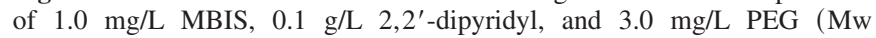
$=8000$ ). (a) 5, (b) 8, (c) 16, and (d) $25 \mathrm{~min}$. roughness that can be a critical issue in narrower trenches. More detailed experiment in terms of the feature dimension and the effect of PEG requires further study.

\section{Conclusion}

The effect of MBIS has been investigated in $\mathrm{Cu}$ electroless deposition. Similar to SPS and DPS, MBIS revealed an accelerating effect at low concentrations and a suppressing effect at high concentrations in the film growth experiments performed on planar substrates. From the half-cell reaction experiments, we found that the acceleration effect of MBIS is mainly associated with the cathodic reactions, while MBIS was observed to have only an inhibition effect in the anodic reaction. When the concentration-dependent effect of MBIS was investigated in trench-patterned substrates, a preferential deposition at the bottom corners was evident, leading to successful superconformal filling in $\mathrm{Cu}$ electroless deposition. Time evolution profiles verified the preferential deposition process, and PEG greatly improved the surface roughness, which is expected to be effective in filling smaller trenches.

\section{Acknowledgments}

The authors are grateful to Dr. Thomas P. Moffat at NIST for helpful discussions. This research was supported by the Nano R\&D program through the Korea Science and Engineering Foundation funded by the Ministry of Education, Science and Technology (no. 2008-02857).

Seoul National University assisted in meeting the publication costs of this article.

\section{References}

1. P. C. Andricacos, C. Uzoh, J. O. Dukovic, J. Horkans, and H. Deligianni, IBM J. Res. Dev., 42, 567 (1998).

2. F. E. Stone, in Electroless Plating: Fundamentals and Applications, G. O. Mallory and J. B. Hajdu, Editors, p. 331, American Electroplaters and Surface Finishers Society, Orlando, FL (1990).

3. Y. Okinaka and T. Osaka, Advances in Electrochemical Science and Engineering, p. 55, VCH, New York (1994).

4. J. J. Kim, S. K. Kim, C. H. Lee, and Y. S. Kim, J. Vac. Sci. Technol. B, 21, 33 (2003).

5. C. H. Lee, S. Hwang, S. C. Kim, and J. J. Kim, Electrochem. Solid-State Lett., 9, C157 (2006)

6. Y. Shacham-Diamand and V. M. Dubin, Microelectron. Eng., 33, 47 (1997)

7. Y. Shacham-Diamand, Electrochem. Solid-State Lett., 3, 279 (2000).

8. C. H. Lee, S. K. Cho, and J. J. Kim, Electrochem. Solid-State Lett., 8, J27 (2005).

9. C. H. Lee, S. C. Lee, and J. J. Kim, Electrochem. Solid-State Lett., 8, C110 (2005).

10. C. H. Lee, S. C. Lee, and J. J. Kim, Electrochim. Acta, 50, 3563 (2005).

11. M. Hasegawa, Y. Okinaka, Y. Shacham-Diamand, and T. Osaka, Electrochem Solid-State Lett., 9, C138 (2006).

12. M. Hasegawa, N. Yamachika, Y. Shacham-Diamand, Y. Okinaka, and T. Osaka, Appl. Phys. Lett., 90, 101916 (2007).

13. T. P. Moffat, J. E. Bonevich, W. H. Huber, A. Stanishevsky, D. R. Kelly, G. R. Stafford, and D. Josell, J. Electrochem. Soc., 147, 4524 (2000).

14. T. P. Moffat, D. Wheeler, M. D. Edelstein, and D. Josell, IBM J. Res. Dev., 49, 19 (2005).

15. C. H. Lee, A. R. Kim, S. K. Kim, H. C. Koo, S. K. Cho, and J. J. Kim, Electrochem. Solid-State Lett., 11, D18 (2008).

16. J. Kivel and J. S. Sallo, J. Electrochem. Soc., 112, 1201 (1965).

17. L. N. Schoenberg, J. Electrochem. Soc., 119, 1491 (1972).

18. F. J. Nuzzi, Plat. Surf. Finish., 70, 51 (1983).

19. J. Li and P. A. Kohl, J. Electrochem. Soc., 149, C631 (2002).

20. F. Hanna, Z. A. Hamid, and A. A. Aal, Mater. Lett., 58, 104 (2004).

21. A. Hung, J. Electrochem. Soc., 132, 1047 (1985).

22. B. J. Feldman and O. R. Melroy, J. Electrochem. Soc., 136, 640 (1989).

23. C. J. Weber, H. W. Pickering, and K. G. Weil, J. Electrochem. Soc., 144, 2364 (1997).

24. Z. Jusys and A. Vaskelis, Electrochim. Acta, 42, 449 (1997). 